\begin{tabular}{c} 
Benha Veterinary Medical Journal \\
$\begin{array}{c}\text { Official Journal Issued by } \\
\text { Faculty of } \\
\text { Veterinary Medicine }\end{array}$ \\
\hline
\end{tabular}

Original Paper

\title{
Prevalence of methicillin-resistant Staphylococcus aureus in some ready-to-eat meat products
}

Marwa Saif ${ }^{1}$, Saad M. Saad ${ }^{2}$, Faten Hasanine ${ }^{2}$, Fahim Shaltout ${ }^{2}$, Marionette Zaghloul ${ }^{1}$

${ }^{I}$ Department of Food Hygiene, Animal Health Research Institute, Benha branch

${ }^{2}$ Department of Food Hygiène, Faculty of Veterinary Medicine, Benha University

\begin{tabular}{|c|c|}
\hline ARTICLE INFO & ABSTRACT \\
\hline $\begin{array}{l}\text { Keywords } \\
\text { Benha city } \\
\text { Meat products } \\
\text { MRSA } \\
\text { PCR } \\
\text { Ready to Eat }\end{array}$ & $\begin{array}{l}\text { Although Staphylococcus aureus (S. aureus) is a bacterium that remains widely studied } \\
\text { because of its high pathogenic potential and its ability to develop resistance to antibiotics } \\
\text { routinely used in clinical practice; this study investigated the occurrence of methicillin- } \\
\text { resistant Staphylococcus aureus (MRSA) in some ready to eat (RTE) meat products collected } \\
\text { from some public restaurants and street vendors in Benha city, Qalubiya governorate, Egypt; } \\
\text { a total of } 120 \text { RTE beef products represented by kofta, burger, shawerma, and luncheon ( } 30 \\
\text { of each) were examined for the prevalence of } S \text {. aureus and molecular detection of MRSA } \\
\text { strains represented by the presence of mecAgene containing isolates; results revealed that } \\
\text { kofta was the most contaminated samples with } S \text {. aureus where the mean count was } 5.2 x 10 \\
\text { CFUlg; followed by burger, shawerma and luncheon samples. Molecular detection of MRSA } \\
\text { isolates carrying mecA gene revealed that out of eight examined isolates, } 2(25 \% \text { of } \\
\text { examined isolates were MRSA strain. The presence of } S \text {. aureus especially MRSA strains in } \\
\text { high prevalence among examined RTE meat products emphasizes the necessity of enforcing } \\
\text { application of strict hygienic measures and GMP during preparation, handling, and serving; } \\
\text { in addition, the health authorities have to exert more control over street vendors and fast food } \\
\text { restaurants. }\end{array}$ \\
\hline
\end{tabular}

\section{INTRODUCTION}

Nowadays, ready to eat (RTE) meat products-based sandwiches of shawerma, kofta, etc. are commonly prepared and sold by many restaurants which are widely distributed all over the country (Takeaway). $S$. aureus is one of the most important microorganisms which can contaminate or re-contaminate cooked foods by workers hands, equipment or utensils (Bryan, 1988). This microorganism is associated with nosocomial and community-acquired staphylococcal infections, primarily related to the emergence of drugresistant organisms (DeLeo and Chambers, 2009). Methicillin-resistant $S$. aureus (MRSA) strains were firstly identified in 1961, immediately after the introduction of methicillin in clinical settings (Barber, 1961). Since then, increased resistance to methicillin among $S$. aureus isolates has been observed globally (Chambers, 1997). Because S. aureus is highly prevalent in food and food environments, MRSA may follow the same transmission pattern, and although MRSA infections have not been associated with the consumption of contaminated meats, the pathogen has entered the food chain. Methicillin-resistant $S$. aureus (MRSA) is mainly attributed to the presence of mecA gene, located on one of Staphylococcal cassette chromosomes mec (SCCmec), that encodes penicillinbinding protein $2 \mathrm{a}$ (PBP2a) with a low affinity for essentially all beta-lactam antimicrobials resulting in difficult treatment of infections (Thaker et al., 2013). Methicillin-resistant S. aureus (MRSA) is known to be one of the most prevalent nosocomial pathogens throughout the world and is capable of causing a wide range of food poisoning, pneumonia, postoperative wound infections and nosocomial infections (Khosravi et al. (2017). In recent years, methicillinresistant S. aureus (MRSA) has been identified in domestic animals and animal-derived food products worldwide (Hanson et al., 2011). Food products surveyed as meat and its products are widely known to be an important reservoir and main source of MRSA in humans (Contreras et al., 2015).

Therefore, the present study was conducted to investigate the incidence of coagulase-positive $S$. aureus and methicillin-resistant S. aureus (MRSA) strains in different popular ready-to-eat meat sandwiches (kofta, burger, shawerma, and luncheon) in Benha city.

\footnotetext{
* Corresponding author Marwa Saif. Department of Food Hygiene, Animal Health Research Institute, Benha branch
} 


\section{MATERIAL AND METHODS}

\subsection{Collection of samples:}

A grand total of 120 samples of RTE meat products represented by "luncheon, burger, shawerma and kofta" (30 of each) were collected from different restaurants and street vendors in Benha city, Qalubiya governorate, Egypt; Samples were transferred to the laboratory under complete aseptic conditions in ice box within one hour and examined for bacteriological and molecular detection of the incidence of $S$. aureus and MRSA strains contamination.

\subsection{Bacteriological examination:}

- Preparation of sample according to APHA (2013).

- Determination of Staphylococci and S. aureus count according to (ISO 6881-1:1999, A1:2003).

- Identification of Staphylococcus aureus.

- Morphological examination (Cruickshank et al., 1975).

- Biochemical identification (MacFaddin, 2000).

\subsection{Molecular detection of MRSA:}

Two isolates of each confirmed coagulase positive $S$. aureus strains from each examined product were sent to the Central Laboratory for Food Analysis, Faculty of Veterinary Medicine, Benha University, Egypt; and molecularly examined for presence of $S$. aureus carrying mecA gene (MRSA) using PCR.

Primer sequences of $S$. aureus used for PCR system following (Jukes et al., 2010) as tabulated in table (1). DNA Extraction using QIA amp kit (Shahet al., 2009). Amplification of $S$. aureus enterotoxin genes (Jukes et al., 2010).

Table 3 Primer sequences of S. aureus used for PCR system.

\begin{tabular}{|c|c|c|c|}
\hline $\begin{array}{l}\text { Target } \\
\text { gene }\end{array}$ & $\begin{array}{l}\text { Oligonucleotide sequence } \\
\left(5^{\prime} \rightarrow 3^{\prime}\right)\end{array}$ & $\begin{array}{l}\text { Product } \\
\text { size (bp) }\end{array}$ & Ref. \\
\hline mecA $(\mathrm{F})$ & 5' TAGAAATGACTGAAC GTCCG '3 & 533 & \\
\hline$m e c A(\mathrm{R})$ & $5^{\prime}$ TTGCGATCA ATGTTACCGTAG ${ }^{\prime 3}$ & 533 & $\begin{array}{l}\text { Jukes et al. } \\
\text { (2010) }\end{array}$ \\
\hline
\end{tabular}

\subsection{Statistical Analysis:}

The obtained results were statistically evaluated by application of Analysis of Variance (ANOVA) test according to Feldman et al. (2003).

\section{RESULTS}

Referring to the results demonstrated in table (2), $S$. aureus could be isolated from $61(50.8 \%)$ samples, represented by $66.6,43.3,36.6,56.6 \%$ with mean counts of $5.2 \times 10,3.2 \times 10,2.6 \times 10$, and $1.9 \times 10 \mathrm{CFU} \backslash \mathrm{g}$ from kofta, burger, shawerma, and luncheon samples, respectively; statistical analysis of variance indicated a significant difference between kofta and the other samples when $\mathrm{p} \leq 0.05$.

Table 2 Statistical analytical results of Staphylococcus aureus in examined ready to eat meat products $(n=30)$

\begin{tabular}{lccccc}
\hline Product & \multicolumn{2}{c}{ Positive samples } & \multicolumn{3}{c}{ S. aureus count (CFUIg) } \\
\hline Product & No. & $\%^{*}$ & Min. & Max. & Mean \pm SE \\
\hline kofta & 17 & 56.6 & $1.2 \times 10$ & $3.3 \times 10$ & $1.9 \times 10^{\mathrm{b}} \pm 0.3 \times 10$ \\
\hline Burger & 13 & 43.3 & $1.0 \times 10$ & $8.0 \times 10$ & $3.2 \times 10^{\mathrm{b}} \pm 0.8 \times 10$ \\
\hline Shawerma & 11 & 36.6 & $1.4 \times 10$ & $5.6 \times 10$ & $2.6 \times 10^{\mathrm{b}} \pm 0.4 \times 10$ \\
\hline Luncheon & 20 & 66.6 & $3.5 \times 10$ & $6.7 \times 10$ & $5.2 \times 10^{\mathrm{a}} \pm 0.4 \times 10$ \\
\hline Total & 61 & $50.8^{* *}$ & & & \\
\hline
\end{tabular}

Values within a column with different superscript letters were significantly different at $(\mathrm{P} \leq 0.05)$. *Percentage in relation to total number of each sample (30). **Percentage in relation to total number of samples (120).

In vitro antibiotic sensitivity test was conducted on 61 $S$. aureus isolates as demonstrated in table (3); although, isolates showed variable sensitivities against different antibiotics, in general, they showed multidrug resistance for about $42.8 \%$ of tested antibiotics represented by Oxacillin $(70.5 \%)$, Methicillin (70.5\%), Nalidixic acid (60.6\%), Amoxicillin (59.0\%), Cefotaxime (55.7\%), and Ampicillin $(50.8 \%)$; while were most sensitive to Norfloxacin $(95.1 \%)$.

Performing of PCR detection of MRSA strains revealed positive detection of $m e c A$ gene band at $533 \mathrm{bp}$ in two isolates out of examined eight isolates $(25 \%)$ as presented in photo (1).

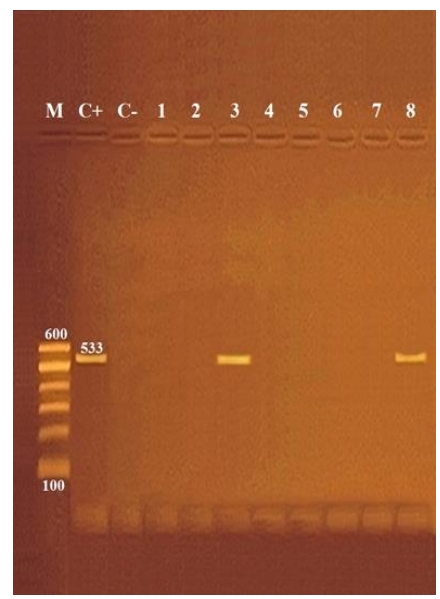

Fig. 1 Agarose gel electrophoresis of multiplex PCR of sea (120 bp), seb (478 bp), sec (257 bp) and sed (317 bp) enterotoxin genes for characterization of S. aureus. Lane M: $100 \mathrm{bp}$ ladder as molecular size DNA marker. Lane C+: Control positive for sea, seb, sec and sed genes. Lane C-: Control negative. Lane 2: Positive S. aureus strain for sea. Lane 3: Positive S. aureus strain for seb gene. Lane 7: Positive $S$. aureus strain for sea and sed genes. Lanes 1, 4, 5, $6 \&$ 8: Negative $S$. aureus for enterotoxins

\section{DISCUSSION}

Since few decades ago, S. aureus was reported as incriminated pathogen in $25 \%$ of all foodborne illnesses in the United States of America; with continuously misuse of antibiotics and emerging multi-drug resistant bacteria, MRSA strains have been aroused as one of the most feared nosocomial germs that play important role in food poisoning; and however low prevalence of MRSA in food, the thread comes from difficulties of treating of infections due to multi-drug resistance of MRSA (Bean et al. (1997); Sciezynska et al. (2012); Cha et al. (2014)).

Recent results revealed that, luncheon samples (consumed immediately without pre heat-treatment) recorded lower $S$. aureus counts than examined preconsumption heated treated samples (kofta, burger, and shawerma); it may be referred to under cooking or improper heat treatment, handling, andlor added chemical preservatives to luncheon during processing that play a direct powerful antimicrobial action against $S$. aureus.

Tabulated results of table (1) were somewhat agreed with those reported by Rawash (2015), Laban (2018) 
who recorded that the incidence of $S$. aureus in their examined RTE kofta, burger, shawerma, and luncheon

was $60,46.6,40$, and $60 \%$, respectively.

Table 3 In Vitro anti-microbial Sensitivity test for isolated S. aureus strains

\begin{tabular}{lcccccccc}
\hline \multirow{2}{*}{ Antimicrobial agents } & Disk & \multicolumn{2}{c}{ Sensitive } & \multicolumn{2}{c}{ Intermediate } & \multicolumn{2}{c}{ Resistant } & \multirow{2}{*}{ AA } \\
\cline { 3 - 6 } & concentrations & No. & $\%$ & No. & $\%$ & No. & $\%$ & \\
\hline Oxacillin & $1 \mu \mathrm{g}$ & 3 & 4.9 & 15 & 24.6 & 43 & 70.5 & $\mathrm{R}$ \\
Methicillin & $5 \mu \mathrm{g}$ & 6 & 9.8 & 12 & 19.6 & 43 & 70.5 & $\mathrm{R}$ \\
Nalidixic acid & $30 \mu \mathrm{g}$ & 6 & 9.8 & 18 & 29.5 & 37 & 60.6 & $\mathrm{R}$ \\
Amoxicillin & $25 \mu \mathrm{g}$ & 9 & 14.7 & 24 & 39.3 & 36 & 59.0 & $\mathrm{R}$ \\
Ampicillin & $20 \mu \mathrm{g}$ & 20 & 32.8 & 10 & 16.3 & 31 & 50.8 & $\mathrm{R}$ \\
Cefotaxime & $30 \mu \mathrm{g}$ & 6 & 9.8 & 21 & 34.4 & 34 & 55.7 & $\mathrm{R}$ \\
Streptomycin & $\mathrm{S} / 10$ & 10 & 16.4 & 33 & 54.1 & 18 & 29.5 & $\mathrm{IS}$ \\
Trimethoprim/ Sulphamethoxazol & $\mathrm{SXT} / 25(1.25 / 23.75) \mathrm{mcg}$ & 21 & 34.4 & 32 & 52.4 & 8 & 13.1 & $\mathrm{IS}$ \\
Neomycin & $30 \mu \mathrm{g}$ & 19 & 31.1 & 32 & 52.5 & 10 & 16.4 & $\mathrm{IS}$ \\
Ciprofloxacin & $5 \mu \mathrm{g}$ & 48 & 78.6 & 6 & 9.8 & 7 & 11.4 & $\mathrm{~S}$ \\
Gentamicin & $10 \mu \mathrm{g}$ & 47 & 77.0 & 10 & 16.4 & 4 & 6.5 & $\mathrm{~S}$ \\
Lomefloxacin & $10 \mu \mathrm{g}$ & 54 & 88.5 & 4 & 6.5 & 3 & 4.9 & $\mathrm{~S}$ \\
Norfloxacin & $10 \mu \mathrm{g}$ & 58 & 95.1 & 0 & 0.0 & 3 & 4.9 & $\mathrm{~S}$ \\
Erythromycin & $15 \mu \mathrm{g}$ & 24 & 39.3 & 35 & 57.3 & 2 & 3.4 & $\mathrm{IS}$ \\
\hline
\end{tabular}

No.: Number of isolates. \%: Percentage in relation to total number of isolates (61). AA: Antibiogram activity. R: Resistant. S: Sensitive. IS: Intermediate

The obtained results have been lower than those recorded by Abd Allah-Mona (2017), Laban (2018), and Morshdy et al. (2018) who recorded that the mean $S$. aureus counts in examined shawerma, kofta, luncheon, and burger samples was $3.9 \times 10^{3}, 6.4 \times 10^{3}$, $2.5 \times 10^{3}$, and $1.9 \times 10^{3} \mathrm{CFU} / \mathrm{g}$, respectively; while they were higher than those recorded by Abd Allah-Enas (2011), Ali and Abd-El-Aziz (2011), and Heweidy (2016) who detected $S$. aureus in 35, 25, 25, 8.6\% of examined kofta, burger, shawerma, and luncheon samples, respectively.

Variations between authors may be attributed to the differences in manufacturing, processing and handling procedures. Presence of $S$. aureus in such RTE foods highlighted preparation, handling, storage or service faults which may come through cross-contamination from raw food, food handlers and the surrounding environment; in addition, spices, equipment, dressings, knives, and other additives are considered as the source of contamination.

Results of antimicrobial sensitivity testas summarized in table (2) were somewhat agreed with the results recorded by Bahbah (2019), Hosny (2016) who recorded a multidrug resistance of their $S$. aureus isolated from meat and meat products. Most of $S$. aureus isolates were resistant to all $\beta$-lactams antibiotics, which is conferred by the mecA gene, which codes for an altered penicillin-binding protein (PBP2a or PBP20) that has a lower affinity for binding $\beta$-lactams (penicillins, cephalosporins, and carbapenems). This allows resistance to all $\beta$-lactam antibiotics and obviates their clinical use during MRSA infections as mentioned by Chambers (2001). From the other hand, results of molecular detection of the presence of MRSA in examined RTE samples were in agreement with Laban (2018); Morshdy et al. (2018) who could detect mecA gene containing $S$. aureus isolates from examined RTE samples.

\section{CONCLUSION}

The high prevalence of $S$. aureus among the tested samples, mainly in kofta and luncheon samples, and the presence of the MRSA in prepared foods highlighted the necessity of enforcing hygienic practices within fast food and street vended foods kitchens. In the future, the molecular and ecological characterization of isolated MRSA strains must be performed to determine the origin of contamination. Better knowledge of strict hygienic practices during collection of raw materials, preparation of food, holding, storage and serving must be educated to food handlers.

\section{REFERENCES}

1. Abd Allah-Enas, M.A. 2011. Microbial and chemical evaluation of fast foods. Thesis, Master of Veterinary Medicine, Benha University, Egypt.

2. Abd Allah-Mona, I. 2016. The proportion of the presence of resistant strains of $S$. aureus isolated from some meat products to antibiotics. Thesis, Master of Veterinary Medicine, Benha University, Egypt.

3. Ali, S.F.H., Abd-El-Aziz, D.M. 2011.Incidence of enterotoxigenic Staphylococcus aureus in some ready-to-eat sandwiches in Assuit city with special reference to methicillin resistant Staphylococcus aureus strains. Assiut Veterinary Medicine Journal, 57(129): 95-106.

4. American Public Health Association "APHA" 2013. Compendium of methods for the microbiological examination of food. T. Matthew Taylor, John N. Sofos, Peter Bodnaruk, and Gary R. Acuff (Eds.), ${ }^{\text {th }}$ Ed., Ch. 2, Washington DC., USA.

5. Bahbah, E.A. 2019.Prevalence of staphylococci in meat products with special reference methicillin-resistant Staphylococcusaureus (MRSA) in Kaliobia governorate.Thesis, Master of Veterinary Medicine, Benha University, Egypt.

6. Barber, M. 1961. Methicillin-resistant staphylococci. J. Clinical Pathology, 14(4):385393.

7. Bean, N.H., Goulding, J.S., Matthew, T.D., Angulo, F.J. 1997. Surveillance for foodborne disease outbreaks-United States, 1988-1992. J. Food Protection, 60(10): 1265-1286. 
8. Bryan, F.L. 1988. Risks associated with vehicles of foodborne pathogens and toxins. J. Food Protection, 51(6): 498-508.

9. Cha, J.D., Choi, S.M., Park, J.H. 2014. Combination of acacetin with antibiotics against methicillin resistant Staphylococcus aureus isolated from clinical specimens. Advances in Bioscience and Biotechnology. 5(4): 398-408.

10. Chambers, H.F. 1997. Methicillin-resistance in staphylococci: molecular and biochemical basis and clinical implications. Clinical Microbiology Reviews, 10(4): 781-791.

11. Chambers, H.F. 2001. The changing epidemiology of Staphylococcus aureus. Emergence of Infectious Diseases, 7(2): 178-182.

12. Contreras, C.P., Nunes Da Silva, L.N., Ferreira, D.C., Ferreira, J.D., Almeida, R.C. 2015. Prevalence of methicillin-resistant Staphylococcus aureus in raw hamburgers and ready-to-eat sandwiches commercialized in supermarkets and fast food outlets in Brazil. J. Food and Nutrition Sciences, 6:1324-1331.

13. Cruickshank, R.; Duguid, J.; Marmion, B. and Swain, R.H. 1975. Medical Microbiology. $12^{\text {th }}$ Ed., Edinburg, London and New York.

14. DeLeo, F.R., Chambers, H.F. 2009. Reemergence of antibiotic-resistant Staphylococcus aureus in the genomics era. J. Clinical Investigations, 119(8): 2464-2474.

15. Feldman, D., Ganon, J., Haffman, R. and Simpson, J. 2003. The solution for data analysis and presentation graphics.2 ${ }^{\text {nd }}$ Ed., Abacus Lancripts, Inc., Berkeley, USA.

16. Hanson, B.M., Dressler, A.E., Harper, A.L., Scheibel, R.P., Wardyn, S.E., Roberts, L.K., Kroeger, J.S., Smith, T.C. 2011. Prevalence of $S$. aureus (MRSA) on retailmeat in Iowa. J. Infection and Public Health, 4(4): 169-174.

17. Heweidy, A.Y. 2016. Prevalence of some foodborne micro-organisms in meat and meat products. Thesis, Master of Veterinary Medicine, Benha University, Egypt.

18. Hosny, D.M.A. 2016. Characterization of methicillin-resistant Staphylococcus aureus (MRSA) isolated from food products of poultry origin in Egypt. Thesis, Master of Veterinary Medicine, Benha University, Egypt.

19. ISO 6888-1:1999, A1:2003. Microbiology of food and animal feeding stuffs - Horizontal method for the enumeration of coagulasepositive staphylococci (Staphylococcus aureus and other species) - Part 1: Technique using Baird-Parker agar medium AMENDMENT 1: Inclusion of precision data.
20. Jukes, L., Mikhail,J., Naledi,B., Hadfield, S.J., H arris, L.G., El-Bouri, K., Davies, B., Mack, D. 2010. Rapid differentiation of Staphylococcus aureus, Staphylococcus epidermidis and other coagulase-negative staphylococci and methicillin susceptibility testing directly from growthpositive blood cultures by multiplex real-time PCR. J. Medical Microbiology, 59:1456-1461.

21. Khosravi, A.D., Jenabi, A., Montazeri, E.A. 2017. Distribution of genes encoding resistance to aminoglycoside modifying enzymes in methicillin-resistant Staphylococcus aureus (MRSA) strains. Kaohsiung J. Medical Sciences, 33(12): 587-593.

22. Konemann, E., Allen, S., Janda, W., Schreckenberger, C., Winn, W. 1997. Color Atlas and Textbook of Diagnostic Microbiology. Fifth Edition, Lippincott, Philadelphia, New York.

23. Laban, R.A. 2018. Detection of methicillinresistant Staphylococcus aureus in some meat products. Thesis, Master of Veterinary Medicine, Zagazig University, Egypt.

24. Lachia, R., Genigeogis, C., Hoeprich, P. 1971. Metachromatic agar-diffusion methods for detecting Staphylococcal nuclease activity. Applied and Environmental Microbiology, 21(4): 585-587.

25. MacFaddin, J. F. 2000.Biochemical tests for identification medical bacteria. Warery Press Inc, Baltimore, Md. 21202 USA.

26. Morshdy, A.M.A., Hussein, M.A., Tharwat, A.E., Fakhry, B.A. 2018. Prevalence of enterotoxigenic and multi-drug resistant Staphylococcus aureus in ready to eat meat sandwiches. Slovenian Veterinary Research, 55(20): 367-374.

27. Rawash, R.A. 2015. Bacteriological status of some ready to eat meat and poultry meat meals in Benha city. Thesis, Master of Veterinary Medicine, Benha University, Egypt.

28. Sciezynska, H., Mackiw, E., Maka, L., Pawlowska, K. 2012. The new microbiological hazards in food. RocznikiPanstwowego ZakladuHigieny, 63(4):397-402.

29. Shah, D., Shringi, S., Besser, T. and Call, D. 2009. Molecular detection of foodborne pathogens, Boca Raton, CRC Press, In: Liu, D. (Ed), Taylor \& Francis group, Florida, USA, Pp. 369-389.

30. Thaker, H.C., Brahmbhatt, M.N., Nayak, J.B. 2013. Isolation and identification of Staphylococcus aureus from milk and milk products and their drug resistance patterns in Anand, Gujarat. Veterinary World J., 6 (1):10-13. 